\title{
Adherence to malaria diagnosis and treatment guidelines among healthcare workers in Ogun State, Nigeria
}

\author{
Oluyomi F. Bamiselu", IkeOluwapo Ajayi ${ }^{1,2}$, Olufunmilayo Fawole², David Dairo², Olufemi Ajumobi ${ }^{1,3}$, \\ Abisola Oladimeji ${ }^{1}$ and Yoon Steven ${ }^{4}$
}

\begin{abstract}
Background: Malaria case management remains a vital component of malaria control strategies. Despite the introduction of national malaria treatment guidelines and scale-up of malaria control interventions in Nigeria, anecdotal evidence shows some deviations from the guidelines in malaria case management. This study assessed factors influencing adherence to malaria diagnosis and treatment guidelines among healthcare workers in public and private sectors in Ogun State, Nigeria.

Methods: A comparative cross-sectional study was carried out among 432 (216 public and 216 private) healthcare workers selected from nine Local Government Areas using a multistage sampling technique. A pre-tested interviewer administered questionnaire was used to collect information on availability and use of malaria Rapid Diagnostic Test (mRDT) and artemisinin combination therapy (ACT), for management of uncomplicated malaria. Adherence was defined as when choice of antimalarials for parasitological confirmed malaria cases was restricted to recommended antimalarial medicines. Association between adherence and independent variables were tested using Chi-square at $5 \%$ level of significance.
\end{abstract}

Results: Malaria RDT was available in $81.9 \%$ of the public health facilities and $19.4 \%$ of the private health facilities $(p=0.001)$. Its use was higher among public healthcare workers (85.2\%) compared to $32.9 \%$ in private facilities $(p=0.000)$. Presumptive diagnosis of malaria was higher among private healthcare workers (94.9\%) compared to $22.7 \%$ public facilities $(p=<0.0001$ ). The main reason for non-usage of mRDT among private healthcare workers was its perceived unreliability of mRDT (40.9\%). Monotherapy including artesunate (58.3\% vs $12.5 \%$ ), amodiaquine (38.9 \% vs $8.3 \%$ ) and chloroquine ( $26.4 \%$ vs $4.2 \%$ ) were significantly more available in private than public health facilities, respectively. Adherence to guidelines was significantly higher among public healthcare workers $(60.6 \%)$ compared to those in private facilities (27.3\%). Availability of antimalarial medicine was the main factor that influenced treatment prescription in both healthcare settings $(p=0.27)$. However, drug promotion by manufactures (45.8\%) has a major influence on private healthcare workers' prescription practice.

Conclusion: The findings of this study demonstrate significant difference between public and private healthcare workers on adherence to national malaria diagnosis and treatment guidelines. Interventions to improve private sector engagement in implementation of the guidelines, training and supply of recommended antimalarial medicines should be intensified.

Keywords: Malaria, National treatment guidelines, Healthcare workers' adherence, Nigeria

(Continued on next page)

\footnotetext{
*Correspondence: yomzie2003@yahoo.com

${ }^{1}$ Nigeria Field Epidemiology and Laboratory Training Programme, Abuja,

Nigeria

Full list of author information is available at the end of the article
} 


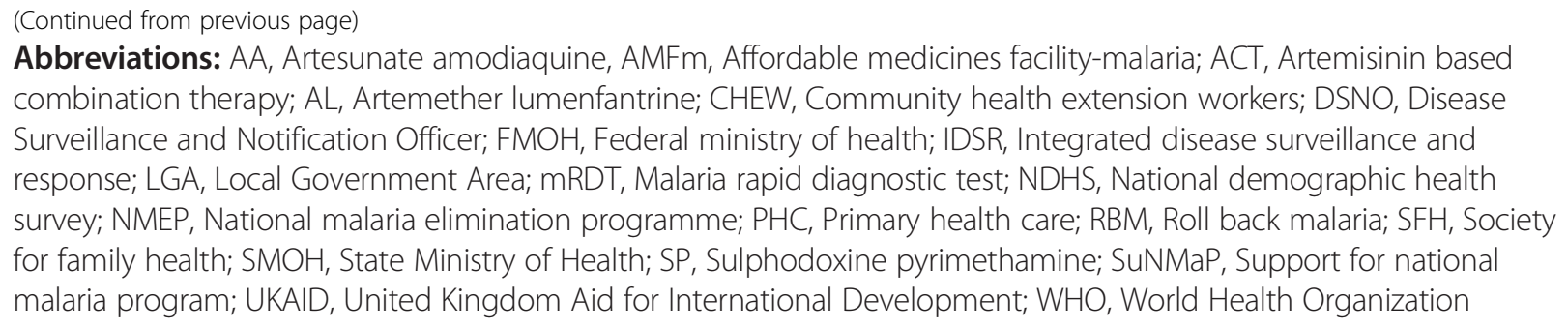

\section{Background}

Malaria is a complex disease that differs in epidemiology and public health impact in different parts of the world. It affects 3.4 billion people, about half of the world's population in 104 countries and territories [1]. The World Health Organisation (WHO) estimates that 198 million cases of malaria occurred globally in 2013 with 584000 deaths [1]. In sub-Saharan Africa, 18 countries account for $80 \%$ of global.malaria infections [1]. Most cases (82\%) and deaths (90\%) occur in Africa, and most deaths (78 \%) are in children under 5 years of age [1]. About $90 \%$ of global malaria deaths occur in 30 countries in sub-Saharan Africa [1]. Nigeria and the Democratic Republic of the Congo together accounted for $39 \%$ of the global total of estimated malaria deaths and $34 \%$ of cases in 2013 [1].

Malaria is a major public health problem in Nigeria, accounting for about $60 \%$ of all outpatient attendances and $30 \%$ of all hospital admissions [2]. It is estimated that malaria is responsible for nearly 110 million clinical cases and an estimated 300,000 deaths per year, including up to $11 \%$ of maternal mortality [2]. Malaria's economic impact is enormous with about N132 billion lost to malaria annually in form of treatment costs, prevention and loss of man hours among other control costs [2]. In Ogun State, malaria is responsible for about $70 \%$ of outpatient attendance at the secondary healthcare facilities and over $80 \%$ of all cases seen in primary healthcare facilities [3]. In 2012, there were 116,372 reported malaria cases in the State with an annual incidence rate of $26 / 1000$ population [3].

Prompt and effective case management of uncomplicated malaria is a critical element of malaria control. These involve accurate clinical assessment, laboratory confirmation of malaria either by malaria rapid diagnostic test (mRDT) or microscopy prior to treatment with an effective antimalarial [4]. Introduction of Artemisininbased combination therapy (ACT) and rapid diagnostic test (RDT) have improved malaria case management substantially. However, development and spread of artemisinin resistance may have dire consequences for the recent achievements in malaria control if health care providers do not adhere to standard diagnostic and treatment guidelines. Thus, it is important to change from symptom-based presumptive treatment to parasitological confirmation of malaria infection before initiation of antimalarial treatment. The use of parasite-based diagnosis allows for efficient utilisation of anti-malarial medicines, and provides an opportunity for other causes of fever to be identified early and treated appropriately [5].

Although the awareness level of the new treatment policy has improved over time, studies have shown that other factors militate against adherence to the national malaria treatment guidelines by healthcare providers [6-8]. Some studies have shown marked variations between health care providers, with clinicians consistently demonstrating retention and use of knowledge and good practice [9-11]. The findings from a study conducted in Mozambique in 2011 demonstrated that public health care workers's adherence to the national guideline for malaria treatment was still poor and prescription of ACT to malaria negative patients remained high [12]. The implementation of effective case management may result in a number of challenges, of which availability of commodities at health facilities and sub-optimal case-management practices are of particular concern. In Nigeria, a study that assessed availability and use of mRDTs in public and private health facilities found limited use of mRDTs in these facilities [11]. The factors that influence case management in both the private and public sector may differ. Some studies in Nigeria reported that primary health care providers had fairly adequate knowledge on basic concepts of malaria but treatment practices were poor [13]. A study conducted in South Eastern Nigeria in 2014 revealed that utilization of ACTs for treating uncomplicated malaria in the States has improved but laboratory confirmation of diagnosis were suboptimum [14]. There is paucity of data on the management of malaria cases provided at health facilities in Ogun state. Clinicians in the private sector are often assumed to use more irrational treatments compare to those in the public sector [15]. The knowledge of health workers' perceptions of the usefulness of RDTs and the influence on their drug prescription practices will provide useful information for promoting effective and improved malaria management. This study was therefore conducted to determine adherence to malaria diagnosis and treatment guideline among health care service providers in public and private sectors in Ogun State, southwest, Nigeria. 


\section{Methods}

\section{Study area}

The study was conducted in Ogun State, southwest Nigeria. Ogun State comprises of 4,624,756 individual disaggregated into 2,294,523 males and 2,330,233 females [16]. The greater proportion of the State lies in the tropical rainforest zone, while the northern part has features of Guinea savannah. The State experiences malaria transmission all year-round with peak transmission during rainy season. The State has three senatorial zones, 20 Local Government Areas (LGAs) and 236 political wards and operates a three-tier health care delivery services namely primary, secondary and tertiary spread across urban and rural areas. The primary healthcare is the first level of contact with individuals and family while the secondary healthcare refers to a second tier of health system, in which patients from primary healthcare are referred to specialist in higher hospitals for treatment. The tertiary healthcare refers to a third level of health system, in which specialized consultative care is provided usually on referral from primary and secondary medical care. The State has a mix of both public and private health facilities totaling 1280 health facilities; disaggregated into 450 Primary health centers (PHCs), 39 secondary facilities, three tertiary facilities (1 State and 2 Federal) and 790 registered privates facilities. Apart from few health facilities that offer only specialized care such as Dental hospitals and Eye clinics, majority of the facilities in the State offer malaria diagnosis and treatment.. Generally, trained staff of public primary health centres/private sector equivalent offer malaria diagnosis using RDT while trained laboratory scientists at public general hospitals/private sector equivalent (secondary care level) offer malaria microscopy and RDT services. Moreover, there are trained staff of these general hospitals/private sector equivalent that can perform RDT. Public health workers were persons employed by the government in tertiary hospitals, secondary hospitals and primary health care workers while private health workers were those employed by health facilities owned by individuals, religious missions and non-governmental organizations (NGOs). It is estimated that about $60 \%$ of people in the State seek medical care in the private health facilities [3].

\section{Study design}

Comparative cross sectional study involving health care providers in public and private health care facilities was carried out. The study was conducted between March and April, 2015.

\section{Sample size and sampling technique}

A total of 432 health workers comprising 216 each in the public and private health facilities participated in this study. They were selected using multistage sampling technique. From each of the three senatorial districts in the State, three LGAs were chosen by random sampling procedure to make a total of nine LGAs. In each of the selected LGA, the health facilities were stratified based on type into public and private, and eight public and private health facilities were selected by ballot from each LGA to make a total of 16 health facilities per LGA. The public health facilities were furthered stratified into primary and secondary health facilities. Overall, 144 health facilities, comprising of 72 each in private and public health sectors were selected. At each health facility, three healthcare workers were selected randomly from the list of all eligible healthcare workers obtained. An eligible worker was one who offered malaria treatment either in public or private health facilities. Overall, 432 healthcare workers were interviewed. Figure 1 shows the flow chart of the sampling method.

\section{Data collection}

Volunteer personnel from Epidemiology unit of Ministry of Health and Local Government Area (LGA) Disease Surveillance and Notification Officers (DSNOs) in the nine selected LGAs were recruited and trained as interviewers. They administered pre-tested semi-structured questionnaires to study participants to obtain information on respondents socio-demographics characteristics, level of awareness of national malaria treatment guideline, availability of mRDTs and ACTs for diagnosis and treatment of malaria, level of adherence to mRDT and ACT use in the health facilities and factors influencing adherence to malaria treatment guidelines. On adherence to use of mRDTs and ACTs the questions were based on current utilization of mRDTs and prescription of antimalarial medicine for diagnosis and treatment of uncomplicated malaria cases respectively. A health facility observational checklist was also administered by interviewer to assess availability of mRDTs, microscopes and the types of antimalarial medicines available at the facilities within the last 3 months.

\section{Data processing and analysis}

The dependent variable was adherence of healthcare worker in public and private health sectors to national treatment guideline for management of uncomplicated malaria. The degree of adherence was classified as strict, partial and nonadherence. Strict adherence was whenther choice of antimalarial medicines for treatment of parasitological confirmed malaria cases were restricted to those recommended in the national guideline for malaria treatment; partial adherence was when there was no parasitological confirmation of cases but choice of antimalarials conformed to recommended national guideline for malaria treatment and nonadherence, when there was no parasitological confirmation of cases and the choice of antimalarial 


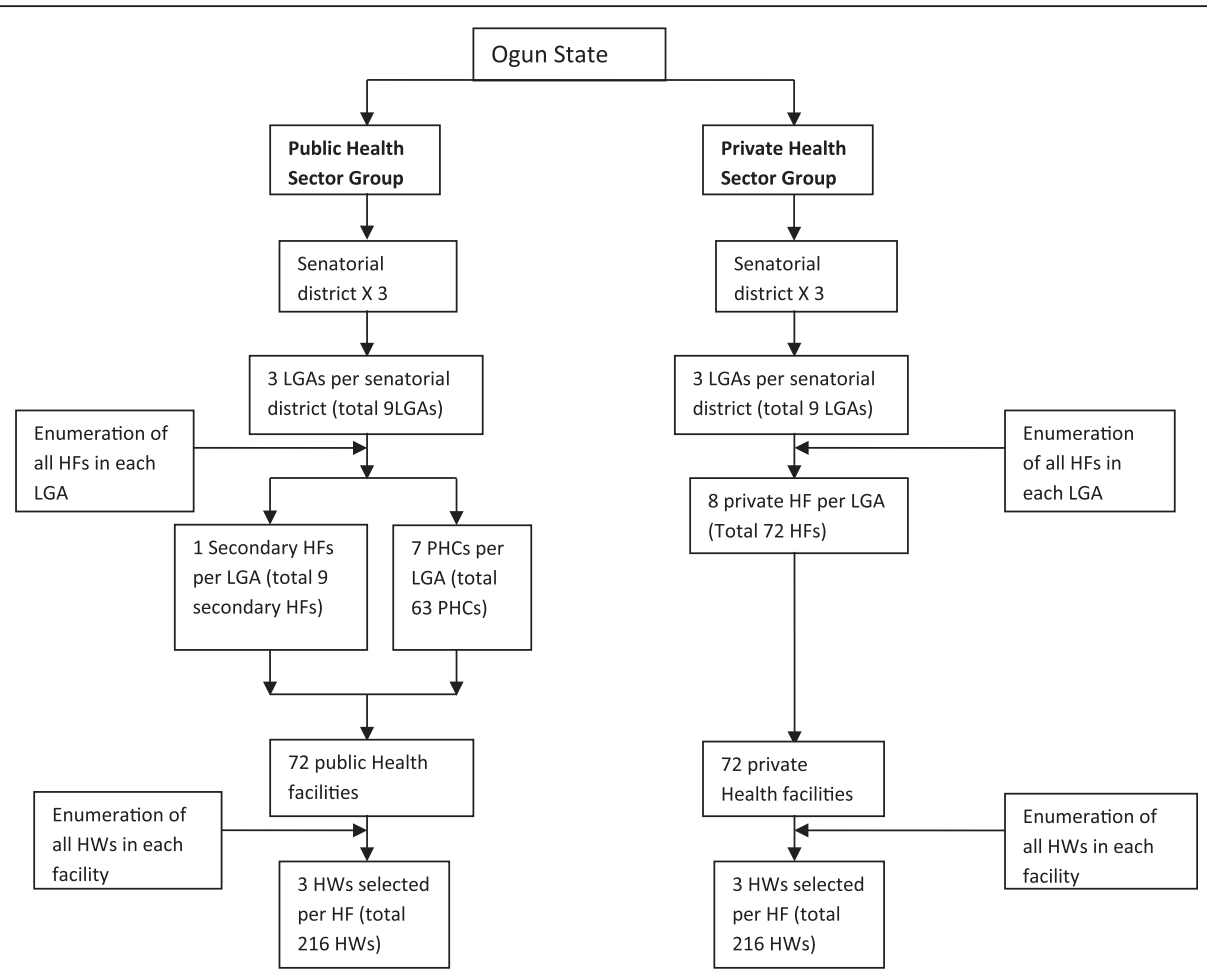

Fig. 1 Flow chart of recruitment of respondents

medicines did not follow the recommendations of the national malaria treatment guideline. Independent variables were categorized into health workers and health facilityrelated factors influencing adherence to national treatment and diagnostic guidelines. Health workers' factors identified were socio-demographic characteristic, cadre of health workers, health workers' knowledge about malaria case management, and access to national guidelines. Health facility factors include availability of functional diagnostic equipment (mRDT and microscope), antimalarial medicines and the national guidelines. Availability of diagnostic equipment and anti-malarial medicines was measured as the proportion of health facilities with at least one functional malaria diagnostic equipment and recommended anti-malarial medicine in stock in the last 3 months before the survey.

Data entry, cleaning and analysis were done using Epi info 3.5.2. The data were cleaned and checked for completeness and outliers before analysis. Descriptive statistics (frequencies, proportions, percentages, means and standard deviations), tables and charts were used to summarize the data. Association between the adherence and independent variables were tested using Chi-square and Fisher's tests and results were considered significant at $p<0.05$.

\section{Ethical considerations}

This research was approved by the Ethics and Research Committee of Ogun State Ministry of Health (Reference number - PH/200/31; Date - 28/11/2014). Participation was voluntary and written informed consent was obtained from all respondents. The participants were not at any point in time exposed to harm as a result of their participation and were free to withdraw their participation at any time during the interview. Confidentiality of collected information was maintained by using non personal identifier codes for the respondents. The completed questionnaire was kept under lock and key.

\section{Results}

\section{Characteristics of respondents}

The socio-demographic characteristics of the respondents are summarized in Table 1. A total of 432 respondents participated in the survey, representing 216 health workers each from public and private health facilities. Overall, majority of the health workers interviewed were females (69.9\%). However, in the private health facilities male respondents $(56.9 \%)$ were more than females (Table 1$)$. The mean age of the respondents was 40.6 years (SD: 8.59). The average age of public and private health workers was 42.1 (SD: 8.4) and 39.1 (SD: 8.6) years, respectively. Majority of respondents from public health facilities $(42.3 \%)$ were aged 45-54 years, while most (44.2\%) from private health facilities were aged 35-44 years. Seven eight percent of health workers in public health facilities mentioned they have been trained on malaria case management while only $24 \%$ of providers in private setting had been trained (Table 1). 
Table 1 Characteristics of the healthcare workers, Ogun State, Nigeria

\begin{tabular}{|c|c|c|c|}
\hline & $\begin{array}{l}\text { Public facilities } \\
N=216 \\
\mathrm{n}(\%)\end{array}$ & $\begin{array}{l}\text { Private facilities } \\
N=216 \\
\text { n (\%) }\end{array}$ & $\begin{array}{l}\text { Total } \\
N=432 \\
\mathrm{n}(\%)\end{array}$ \\
\hline \multicolumn{4}{|l|}{ Gender } \\
\hline Male & $37(17.1)$ & $93(43.1)$ & $130(30.1)$ \\
\hline Female & $179(82.8)$ & $123(56.9)$ & $302(69.9)$ \\
\hline \multicolumn{4}{|l|}{ Age (years) } \\
\hline$<25$ & $4(1.9)$ & $6(2.8)$ & $10(2.3)$ \\
\hline $25-34$ & $36(16.7)$ & $64(29.6)$ & $100(23.1)$ \\
\hline $35-44$ & 79 (36.6) & $95(43.9)$ & $174(40.3)$ \\
\hline $45-54$ & $89(41.2)$ & $40(18.5)$ & $129(29.9)$ \\
\hline$\geq 55$ & $8(3.7)$ & $11(5.1)$ & $19(4.4)$ \\
\hline \multicolumn{4}{|l|}{ Cadre of Health workers } \\
\hline Consultant & 0 & $4(1.9)$ & $4(0.9)$ \\
\hline Medical Officer & $25(11.6)$ & $110(51.6)$ & $135(31.5)$ \\
\hline Nurse/Midwife & $99(46.0)$ & $92(43.2)$ & $191(44.6)$ \\
\hline $\mathrm{CHEW} / \mathrm{CHO}^{\mathrm{a}}$ & $89(41.4)$ & $7(3.3)$ & $96(22.4)$ \\
\hline Laboratory Scientist & $2(0.9)$ & 0 & $2(0.5)$ \\
\hline \multicolumn{4}{|l|}{ Years of practice } \\
\hline $1-5$ & $21(9.7)$ & $43(19.9)$ & $64(14.8)$ \\
\hline $6-10$ & $37(17.1)$ & $60(17.1)$ & $97(22.5)$ \\
\hline $11-15$ & $32((14.8)$ & $62(28.7)$ & $94(21.8)$ \\
\hline $16-20$ & $43(19.9)$ & $20(9.3)$ & $63(14.6)$ \\
\hline $21-25$ & $46((21.3)$ & $14(6.5)$ & $60(13.9)$ \\
\hline$>25$ & $37(17.2)$ & $17(7.9)$ & $54(12.5)$ \\
\hline \multicolumn{4}{|c|}{ Training on malaria case management } \\
\hline Yes & $170(79.4)$ & $52(20.2)$ & $222(51.2)$ \\
\hline No & $46(21.3)$ & $164(75.9)$ & $210(48.6)$ \\
\hline
\end{tabular}

CHEW Community Health Extension Worker; $\mathrm{CHO}$ Community Health Officers ${ }^{a}$ These cadre of health workere were group together because they are expected to work mainly at community level

\section{Characteristics of health facilities}

Overall $50.7 \%$ of the health facilities [81.9\% of public health facilities compared with $19.1 \%$ of private health facilities] had mRDT kits in stock in the last 3 months prior to survey (Table 2). Seventeen percent and $25.0 \%$ of the public and private facilities respectively used microscopy, $(p=0.22)$.

Overall, artemether-lumefantrine (AL) was the most available (86.8 \%) among all the recommended antimalarial medicines in the national malaria treatment guideline (Table 2). Artesunate-amodiaquine (AA) was available in $76.4 \%$ of the facilities. Artemether-lumefantrine and AA were more often available in public facilities $(94.4 \%$ and $79.2 \%)$ than in private facilities $(79.2 \%$ and $72.2 \%)$, respectively. However, only the difference in availability of $\mathrm{AL}$ in the two facilities was significant. $(p=0.007)$. There were significant differences in the proportion of quinine tablet $(84.7 \%$ vs $36.1 \%)$ and quinine injection (59.7\% vs $25.0 \%$ ) available in public and private facilities, respectively. A higher proportion of the public health facilities had sulfadoxine-pyrimethamine in stock (90.3 \%) compared to the private facilities $(76.4 \%),(p=0.03)$.

Artesunate (monotherapy) was the most common of the non-recommended antimalarial medicines stocked in the facilities $(35.4 \%)$ with a significant difference in the proportion of private facilities (58.3\%) compared with public facilities $(12.5 \%)$. Twenty seven percent of the private health facilities stocked chloroquine in their facility, compared to $4.2 \%$ public health facilities $(p=0.0002)$. Amodiaquine tablets were available in $38.9 \%$ private health facilities and $8.3 \%$ of public health facilities.

\section{Awareness of national malaria treatment guidelines and use} of the guidelines in management of uncomplicated malaria Of the 216 health care workers each from the public and private facilities, $212(98.2 \%)$ and 205 (94.9\%) were aware of the national malaria treatment guidelines, 144 (66.6\%) and $59(27.3 \%)$ had access to the guideline out of which 130 (90.3\%) and 29 (49.2\%) reported using the guidelines, respectively, $p=0.001$ (Fig. 2).

\section{Providers' knowledge of malaria case management}

A high proportion $(85.7 \%)$ of the health workers interviewed in public health facilities stated the recommended doses of ACT for adults correctly compared to $66.7 \%$ of health workers interviewed in private health facilities $(p=0.000)$. Almost all $(95.7 \%)$ health workers interviewed in public facilities and $93.5 \%$ of health workers interviewed in private facilities responded correctly that food should be taken before using ACT $(p=0.40)$. However, $65.7 \%$ and $47.3 \%$ of the health workers in public and private health facilities, respectively knew that a fatty meal and milk are important for improving drug absorption of artemether lumenfantrine brand of ACT $(p=0.0002)$.

\section{Malaria diagnosis methods}

Presumptive diagnosis was significantly more likely to be carried out in private health facilities $(94.9 \%)$ than public health facilities $(22.7 \%),(p=0.000)$ while parasitological diagnosis using RDT was more likely to be used by health workers in public facilities (85.2 \%) compared to private facilities $(32.9 \%),(p=0.000)$. The main reasons reported by respondents for non-use of RDT were non-availability of RDT (42.3\%) among the public health workers and lack of confidence in RDT results $(40.9 \%)$ among health workers in private facilities.

\section{Adherence to national antimalarial treatment guideline when choosing antimalarials for treatment of parasitological confirmed malaria cases}

Almost half of all the health workers interviewed $(n=186$, $44.1 \%$ ) adhered strictly to the national treatment guideline 
Table $\mathbf{2}$ Characteristics of the selected health facilities

\begin{tabular}{|c|c|c|c|c|c|}
\hline & $\begin{array}{l}\text { Public facilities } \\
N=72 \\
\mathrm{n}(\%)\end{array}$ & $\begin{array}{l}\text { Private facilities } \\
N=72 \\
\mathrm{n}(\%)\end{array}$ & $\begin{array}{l}\text { Total } \\
N=144 \\
\mathrm{n}(\%)\end{array}$ & ${ }^{\mathrm{a}} \mathrm{OR}(95 \% \mathrm{Cl})$ & $P$-value \\
\hline \multicolumn{6}{|l|}{ Availability of malaria diagnostic equipment } \\
\hline HF with microscopy & $12(16.7 \%)$ & $18(25.0 \%)$ & $30(20.8 \%)$ & $0.6(0.3-1.4)$ & 0.220 \\
\hline HF with mRDT & $59(81.9 \%))$ & $14(19.4 \%)$ & $73(50.7 \%)$ & $18.8(8.1-3.4)$ & 0.000 \\
\hline HF with both microscopy and mRDT & $7(9.7 \%)$ & $8(11.1 \%)$ & $15(10.4 \%)$ & $0.9(0.3-2.5)$ & 0.790 \\
\hline \multicolumn{6}{|c|}{ Availability of recommended antimalarial medicines } \\
\hline $\mathrm{AL}$ & $68(94.4)$ & $57(79.2)$ & $125(86.8)$ & $4.5(1.4-14.2)$ & 0.007 \\
\hline AA & $58(80.6)$ & $52(72.2)$ & $110(76.4)$ & $1.6(0.7-3.5)$ & 0.240 \\
\hline Quinine tab & $61(84.7)$ & $26(36.1)$ & $87(60.4)$ & $9.8(4.4-21.9)$ & 0.000 \\
\hline Quinine Inj. & $43(59.7)$ & $18(25.0)$ & $61(42.4)$ & $4.5(2.2-9.1)$ & 0.000 \\
\hline Artemether Inj. & $8(11.1)$ & $40(55.6)$ & $48(33.3)$ & $0.1(0.0-0.2)$ & 0.000 \\
\hline S-P & $65(90.3)$ & $55(76.4)$ & $120(83.3)$ & $2.9(1.1-7.4)$ & 0.030 \\
\hline \multicolumn{6}{|l|}{ Non recommended antimalarial medicines } \\
\hline Artesunate & $9(12.5)$ & $42(58.3)$ & $51(35.4)$ & $0.1(0.0-0.2)$ & 0.000 \\
\hline Amodiaquine & $6(8.3)$ & $28(38.9)$ & $34(23.6)$ & $0.1(0.0-0.4)$ & 0.0002 \\
\hline Chloroquine & $3(4.2)$ & $19(26.4)$ & $22(15.3)$ & $0.1(0.0-0.4)$ & 0.002 \\
\hline Halofantrine & $2(2.8)$ & $8(11.1)$ & $10(6.9)$ & $0.2(0.1-1.1)$ & 0.050 \\
\hline Dihydroartemisinin-piperaquine & $2(2.8)$ & $5(6.9)$ & $7(4.9)$ & $0.4(0.1-2.0)$ & 0.250 \\
\hline
\end{tabular}

in the choice of antimalarial medicines for parasitological confirmed malaria cases (Table 3). These included 129 (60.6\%) in public and 57 (27.3\%) in private health facilities. Sixty one $(28.6 \%)$ public health workers and 77 (36.8 \%) private health workers partially adhered to the guideline when choosing antimalarials without parasitological confirmation. Non-adherence to prescription of recommended antimalarial medicines and laboratory confirmation was reported among $33.9 \%$ of private health workers compared to $11.3 \%$ of public health worker $(p<0.001)$.

\section{Health workers' factors associated with adherence to national malaria treatment guideline}

Table 4 - shows health workers' factors associated with adherence to national treatment guideline. Health workers in both public $(\mathrm{OR}=4.3,95 \% \mathrm{CI}=1.7-10.9)$ and private $(\mathrm{OR}=7.0, \quad 95 \% \mathrm{CI}=3.3-14.7) \quad$ health settings using malaria diagnostic method had significantly higher odds of adhering to the guideline. Training on malaria case management, access to the guidelines and availability of malaria diagnostic tool were not associated with

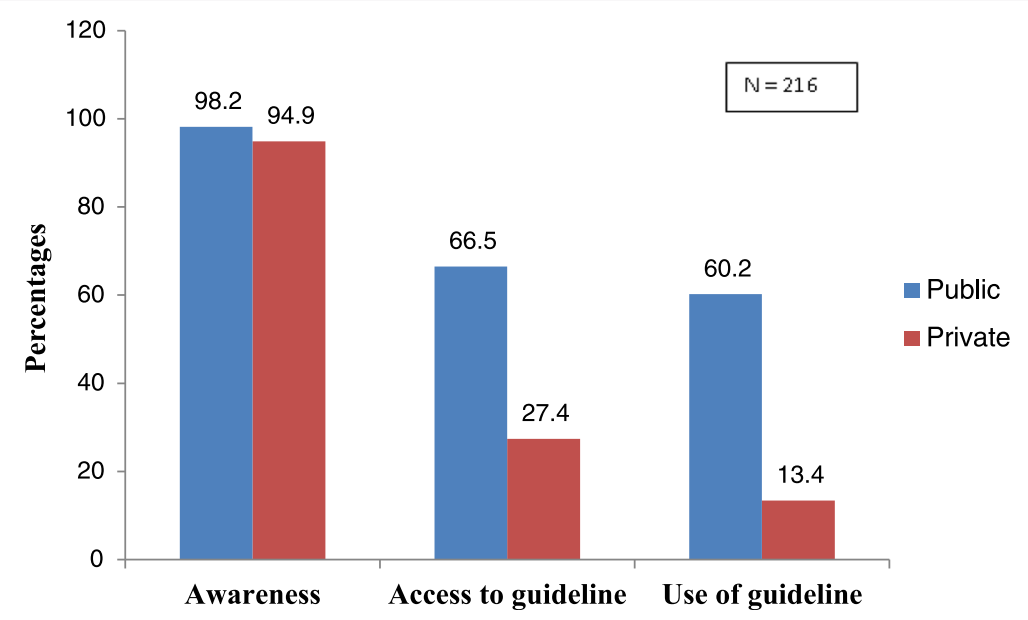

Fig. 2 Awareness, accessibility and use of National malaria treatment guidelines among health workers in public and private health facilities in Ogun State, Nigeria 
Table 3 Adherence to the national malaria treatment guidelines by health workers when choosing medicines for malaria treatment

\begin{tabular}{|c|c|c|c|c|c|}
\hline $\begin{array}{l}\text { Level of adherence } \\
\text { to malaria treatment } \\
\text { guidelines }\end{array}$ & $\begin{array}{l}\text { Public } \\
N=206 \\
\mathrm{n}(\%)\end{array}$ & $\begin{array}{l}\text { Private } \\
N=205 \\
\mathrm{n}(\%)\end{array}$ & $\begin{array}{l}\text { Total } \\
N=411 \\
\mathrm{n}(\%)\end{array}$ & & $P$-value \\
\hline Strictly adhered & $129(60.6)$ & $57(27.3)$ & $186(44.1)$ & & \\
\hline Partially adhered & $61(28.6)$ & 77 (36.8) & $138(32.7)$ & $0.69(0.5-1.2)$ & 0.07 \\
\hline id not adhere & $24(11.3)$ & 71 (33.9) & 95 (22.5) & $0.25(0.2-0.4)$ & 0.000 \\
\hline
\end{tabular}

${ }^{\text {aOR Odd Ratio }}$

adherence to the guidelines in both public and private health facilities.

Factors influencing type of antimalarial drugs prescribed Majority of the providers in both public (66.7\%) and private $(61.6 \%)$ settings considered availability of the antimalarial medicines before prescribing a specific antimalarial medicine to the patients, $p=0.27$ (Table 5). However, $64.8 \%$ of health workers in public facilities and $36.5 \%$ in private facilities considered the recommendations of the treatment guidelines before commencing treatment $(p<0.0001)$. Drug promotion was reported among $8.8 \%$ health worker in public and $45.8 \%$ in private health facilities $(p=0.000)$. Patient preferences, need to make profit, and patients request were mentioned by $18.5 \%, 10.2 \%$ and $5.6 \%$ respectively in private health facilities, to influence treatment provided compared to $3.7 \%, 0.5 \%$, and $0.9 \%$ among those in public health facilities, respectively $(p<0.05)$.

\section{Discussion}

The study showed high level of awareness of national treatment guideline among health workers in public and private settings. Malaria RDT was more available in the public health facilities and also was its use for parasitological diagnosis of malaria. Presumptive diagnosis of malaria was higher among private healthcare workers and the main reason for non-usage of mRDT was perceived non reliability of mRDT results. The recommended ACTs were available in high proportion in both private and public health facilities but monotherapy antimalarial medicines, such as artesunate, amodiaquine and chloroquine were significantly more available in the private facilities. Adherence to national diagnosis and treatment guidelines was significantly higher among public healthcare workers (60.6 \%) compared to those in private facilities $(27.3 \%)$. The type of antimalarial available in facility stocks influenced treatment prescription in both healthcare settings. Drug promotion by manufactures $(45.8 \%)$ had a major influence on private healthcare workers' prescription practice.

This study findings indicate that high level of awareness of national treatment guideline was demonstrated among health workers in both public (98.1\%) and private $(94.8 \%)$ settings This is in contrast to a study done in Tanzania which revealed that $15.5 \%$ of health care workers were aware of the country's guidelines [17]. Twenty percent of the health workers in private sector had received training on case management of malaria within the last 3 years. This proportion is less than that reported in a study done in Kenya where $46 \%$ of private health workers received training on malaria treatment [9]. The health worker's knowledge of malaria case management was generally lower in the private sector than in the public sector. This is similar to findings from other studies which showed that health workers' knowledge of drugs and dose regimens, particularly in the private sector, is often poor [18].

Rapid diagnostic test kits were more available in the public health facilities $(82.0 \%)$ than private health facilities (19.2\%). This finding underscores the need to scale-up mRDTs among private health facilities since a majority (about $60 \%$ ) of the populace in the State patronize them [19]. Currently, mRDTs are supplied free of charge by government to public primary health facilities and this may have accounted for the better availability of mRDT in public facilities. Majority of the health workers interviewed

Table 4 Health worker factors associated with adherence to national malaria treatment guidelines

\begin{tabular}{|c|c|c|c|c|c|c|c|}
\hline Characteristics & & \multicolumn{3}{|c|}{ Public health facilities } & \multicolumn{3}{|c|}{ Private health facilities } \\
\hline \multirow{2}{*}{$\begin{array}{l}\text { Provider knowledge of medicine } \\
\text { of choice for malaria treatment } \\
\text { and dosing regimens }\end{array}$} & Had knowledge & $127(100)$ & $52(81.3)$ & - & $71(100)$ & $69(52.7)$ & - \\
\hline & Didn't have & 0 & $23(18.7)$ & Ref & 0 & $62(47.3)$ & Ref \\
\hline \multirow{2}{*}{$\begin{array}{l}\text { Health workers who had access } \\
\text { to the guidelines }\end{array}$} & Had access to guidelines & $71(64.6)$ & $66(66.7)$ & $0.9(0.5-1.6)$ & $19(26.0)$ & $40(34.2)$ & $0.67(0.4-1.3)$ \\
\hline & Didn't have & $39(35.5)$ & $33(33.3)$ & Ref & $54(73.9)$ & $77(65.8)$ & Ref \\
\hline \multirow{2}{*}{$\begin{array}{l}\text { Health workers used any malaria } \\
\text { diagnostic tool (RDT or microscopy) }\end{array}$} & Used diagnostic tool & $128(94.8)$ & $68(81.0)$ & $4.3(1.7-10.9)$ & $65(85.5)$ & $49(45.8)$ & $7.0(3.3-14.7)$ \\
\hline & Didn't use & $7(5.2)$ & $16(19.1)$ & Ref & $11(14.5)$ & $58(58.5)$ & Ref \\
\hline \multirow{2}{*}{$\begin{array}{l}\text { Training on malaria case } \\
\text { management }\end{array}$} & Received training & $82(73.9)$ & $85(84.2)$ & $0.5(0.3-1.1)$ & $13(18.1)$ & $37(27.2)$ & $0.6(0.3-1.2$ \\
\hline & Didn't receive & $29(26.1)$ & $16(15.8)$ & Ref & $59(81.9)$ & $99(72.8)$ & Ref \\
\hline
\end{tabular}

${ }^{a}$ Adhere' is strict adherence: both parasitological diagnosis and appropriate treatment i.e. only positive cases of uncomplicated malaria received ACTs ${ }^{\mathrm{b}} \mathrm{OR}$ Odd Ratio 
Table 5 Factors influencing type of antimalarial drugs prescribed by health workers

\begin{tabular}{|c|c|c|c|c|c|}
\hline & $\begin{array}{l}\text { Public } \\
N=216 \\
n(\%)\end{array}$ & $\begin{array}{l}\text { Private } \\
N=216 \\
\mathrm{n}(\%)\end{array}$ & $\begin{array}{l}\text { Total } \\
N=432 \\
\mathrm{n}(\%)\end{array}$ & OR $(95 \% \mathrm{Cl})$ & $P$-value \\
\hline Drugs availability & $144(66.7)$ & $133(61.6)$ & $277(64.1)$ & $1.25(0.8-1.9)$ & 0.27 \\
\hline Existing national malaria treatment guidelines & $140(64.8)$ & $79(36.5)$ & $219(50.7)$ & $3.19(2.2-4.7)$ & 0.000 \\
\hline Drug promotion by manufacturers & $19(8.8)$ & $99(45.8)$ & $118(27.3)$ & $0.11(0.1-0.2)$ & 0.000 \\
\hline Idea of what the consumer prefers & $8(3.7)$ & $40(18.5)$ & $48(11.1)$ & $0.16(0.8-0.4)$ & 0.0002 \\
\hline Need to make profit & $1(0.5)$ & $22(10.2)$ & $23(5.3)$ & $0.04(0.0-0.3)$ & 0.0001 \\
\hline Demand by patients & $2(0.9)$ & $12(5.6)$ & $24(5.6)$ & $0.15(0.0-0.7)$ & 0.01 \\
\hline
\end{tabular}

from public health facilities also used mRDTs (85.2\%) compared to health workers in private setting (32.9\%). Some of the limitations of the use of mRDTs as noted by the health workers in private setting include cost and availability of mRDT. This is likely to promote treatment based on presumptive diagnosis of malaria by health workers in private health facilities. A positive finding however, was that health workers in both public and private facilities knew that mRDT could be affected by temperature and humidity. This is important for maintaining the quality of mRDT in the facilities.

The availability of the recommended ACT in the public $(94.2 \%)$ and private $(79.9 \%)$ sectors is commendable and shows the level of confidence the health facilities has in ACT and to some extent, the effect of initiatives such as affordable medicine facility for malaria (AMFm) and private sector co-payment mechanism that subsidize cost of ACTs in private and support for ACTs in public sector from Global Fund grants, United States Presidents' Malaria Initiatives (PMI) and United Kingdom Aid for International Development (UKAID). This is a positive findings in the push to improve the case management of malaria in the State. It also indicates the progress made over the years when compared to results of a study on malaria control practice done in 2010 which showed that less than a fifth of the primary and secondary health facilities used the recommended ACT [20]. Artemisinin-based combination therapy (ACTs) especially the recommended firstline groups in the national treatment guidelines $\mathrm{AL}$ and co-formulated artesunat amodiaquine (AA) were readily available in public facilities. This could be attributed to the fact that ACTs donated by grant/donors are currently supplied free of charge for treatment of all parasitological confirmed malaria cases in public primary health facilities in the State (Ogun State Malaria Activities Report, 2012). Overall the availability of ACTs were lower in private sector compare to public sector but were more available in both types of facilities than mRDTs and microscopy. However, the fact that ACTs were readily available and were used, suggest that some patients particularly at private health facilities may be treated with ACTs without laboratory diagnosis. Parasitological diagnosis is a component of malaria case management, the first step without which adherence to national guidelines is incomplete. Improper and abusive use of ACTs without confirmatory diagnosis will result in negative clinical and economic impact [21].

The findings of this study also revealed that monotherapies, either as oral artemisinin-based (Artesunate) or nonartemisinin-based (Amodiaquine) were in stock for use in a sizeable proportion (58.3\% and $39.4 \%$ ), respectively in the private facilities. The use of artemisinin-based monotherapy is contrary to national policy and portend potential risk of parasite developing resistance to the medicine as a result of its short half-life [2]. Non-artemisinin monotherapies, typically chloroquine $(26.9 \%)$ which has been proscribed was significantly more available for use in private health facilities compared to public health facilities and were usually sold at a much lower price than ACTs. Given the relative affordability and accessibility of non-artemisinin therapies, health workers at private health facilities are likely to choose incorrect and ineffective anti-malarial drugs for treatment of malaria. This finding is similar to results of a study done in Anambra, southeastern Nigeria which assessed the quality of antimalarial drugs provided by public and private health care providers and found that monotherapies such as chloroquine, SP, quinine, artesunate and dihydroartemisinin were still widely used for treatment of malaria [15].

Health workers who used any of the malaria laboratory diagnostic method (RDT or microscopy) were significantly more likely to adhere to national treatment guideline in both the public and private health facilities. This finding was similar to study by Marycelina et al. in Tanzania where health workers overall adherence to national treatment guideline was $90.5 \%$ [22]. The study failed to find an association between case management training of public and private health workers and adherence to guidelines. This was consistent with other studies showing that being trained does not necessarily translate into correct behavior $[23,24]$. Availability of antimalarial drugs was observed to be a major factor that affected treatment prescription of both public and private health setting. This implied that health workers are sometime constrained to prescribe the antimalarial drugs available in the facilities even if they are 
not the recommended ones. This supports the results of earlier studies that found that prescribing patterns are more likely to follow availability of antimalarial drugs [25]. In this study, drug promotion by manufacturers to the providers was a significant factor that influences drug prescribed by health workers in private setting. This is worrisome because it could lead to supplier-induced demand and prescription of unnecessary drugs thereby worsening the economic burden of the disease on the consumers and predisposing to development of drug resistance if the drugs are wrongly used. The factors found to influence health workers' malaria treatment prescription behavior constitute focus to targets in the planning of intervention to improve the treatment of malaria in health facilities in the state.

\section{Study limitations}

The interviews and discussions were conducted at the heath facilities and the questionnaire captured self-reported information and relied primarily on respondents providing the right information. There might have been some reporting bias by respondents due to fear of disclosing information that respondents believed could tarnish the image of their health facility. Hence there is probably the tendency to overestimate adherence in this study since this is a desirable outcome. However this was minimized by ensuring that participants were interviewed in a secluded place whereby a high degree of privacy was observed and reassured that the information obtained will be used solely for research purposes.. Some health facilities data records were incompletely filled, and this affected the completeness of the information obtained using the health facility inventory checklist.

\section{Conclusion}

The findings of this study found close similarity in the level of awareness of the national malaria treatment guidelines, but a remarkable difference in compliance to appropriate case management of uncomplicated malaria between public and private health facilities in the State. In general, health workers in both public and private sectors had fairly good knowledge on the national malaria treatment guidelines for case management of uncomplicated malaria. Majority of health workers in private setting were not using RDTs because of perceived unreliability, high cost and irregular supply. Also presumptive diagnosis and use of antimalarial monotherapy drugs are still common practices among providers in private health setting. This may increase the risk of development of parasite resistance to the currently effective anti-malarial medicines and treatment failures, thereby undermining the goals of malaria treatment guidelines/policy. Availability of drugs influenced malaria treatment prescription behavior of providers in both health settings. However drug promotion by manufacturers may influence prescribing practices among private providers. Therefore, in order to improve the implementation process of the national malaria diagnosis and treatment guidelines, there is need to intensify strategies to enhance appropriate malaria case management in private sector and address factors influencing adherence to national guideline. Provision of mRDT and ACTs by the government to private health facilities as done for the public sector will help to ameliorate the influence of drug manufacturers.

\section{Acknowledgements \\ This study was supported by Nigeria Field Epidemiology and Laboratory Training Programme (NFELTP). We would like to thank the entire staff of the Department of Public Health of Ogun State Ministry of Health and the Local Government Disease Surveillance Officers (DSNOs) for their wholehearted support during fieldwork. Finally, the authors would like to express their sincere gratitude to the health care workers who participated in this study.}

\section{Funding}

This study was supported by cooperative agreement number U2R6H000046 funded by the Center for Disease Control and Prevention (CDC) through the Nigeria Field Epidemiology and Laboratory Training Programme(NFELTP). Its contents are solely the responsibility of the author's and do not necessarily represent the official views of the CDC or the Department of Health and Human Services.

\section{Availability of data and materials}

Data will not be shared since the data used in this article are part of a larger database that is still being analyzed to produce another article.

\section{Authors' contributions}

BFO participated in the study design, data collection, data analysis, was a study investigator and drafted the manuscript for input by the other authors. Al contributed to study and questionnaire design and provided input to the manuscript, FF contributed to study and questionnaire design and provided input to the manuscript, DD participated in the study and questionnaire design and acted as academic supervisor to the project. AO and OA participated in the writing of the manuscript. SY provided input to the manuscript. All authors read and approved the final manuscript.

\section{Competing interests}

The authors declare that they have no competing interests.

\section{Consent for publication}

There is no image or details of any individual reported within the manuscript that require consent for publication.

Ethics approval and consent to participate

The study protocol was granted approval by the Ethics and Research Committee of Ogun State Ministry of Health. Participation was voluntary and the participants were free to stop during the data collection process. Written informed consent was obtained from the study participants after they were fully informed about the procedures involved in the research. Written informed consent was obtained from the study participants after they were fully informed about the procedures involved in the research.

\section{Endnotes}

We used Mendeley reference manager in this manuscript.

\section{Author details}

'Nigeria Field Epidemiology and Laboratory Training Programme, Abuja, Nigeria. ${ }^{2}$ Department of Epidemiology and Medical Statistics, Faculty of Public Health, University of Ibadan, Ibadan, Nigeria. ${ }^{3}$ National Malaria Elimination Programme, Abuja, Nigeria. ${ }^{4}$ Division of Parasitic Diseases and Malaria, Center for Global Health, Centers for Disease Control and Prevention, Atlanta, Georgia. 
Received: 4 January 2016 Accepted: 12 August 2016

Published online: 19 August 2016

\section{References}

1. WHO. WHO: World malaria report 2013. Geneva: World Health Organization; 2013.

2. NMCP/FMOH. Federal Ministry of Health, National Malaria Control Programme; A 5-year Strategic Plan: 2006-2010. 2006.

3. SMOH. Ogun State Ministry of Health. Malaria Control Activities Report. 2012

4. WHO. Guidelines for the treatment of malaria, Second Edition. Geneva: World Health Organization; 2010.

5. Lubell Y, Reyburn H, Mbakilwa H, Mwangi R, Chonya S, Whitty CJM, et al. The impact of response to the results of diagnostic tests for malaria: costbenefit analysis. BMJ. 2008;336:202-5.

6. Chandler CIR, Jones C, Boniface G, Juma K, Reyburn H, Whitty CJM. Guidelines and mindlines: why do clinical staff over-diagnose malaria in Tanzania? A qualitative study. Malar J. 2008;7:53.

7. Ogbonna A, Uneke C. Artemisinin-based combination therapy for uncomplicated malaria in sub-Saharan Africa: The efficacy, safety, resistance and policy. Trans $\mathrm{R}$ Soc Trop Med Hyg. 2008;102:621-7.

8. Harner D, Ndhlovu M, Zurovac D, Fox M, Yeboah-Antwi K, Chanda P, et al. Improved diagnostic testing and malaria treatment practices in Zambia. JAMA. 2006;297(20):2227-31.

9. Zurovac D, Zurovac D, Rowe a K, Ochola SA, Noor a M, Midia B, English M, et al. Predictors of the quality of health worker treatment practices for uncomplicated malaria at government health facilities in Kenya. Int J Epidemiol. 2004;33:1080-91.

10. Chandler CIR, Mwangi R, Mbakilwa H, Olomi R, Whitty CJM, Reyburn H. Malaria overdiagnosis: Is patient pressure the problem? Health Policy Plan. 2008:23:170-8

11. Uzochukwu BSC, Chiegboka LO, Enwereuzo C, Nwosu U, Okorafor D, Onwujekwe OE, et al. Examining appropriate diagnosis and treatment of malaria: availability and use of rapid diagnostic tests and artemisinin-based combination therapy in public and private health facilities in south east Nigeria. BMC Public Health. 2010;10:486.

12. Salomão CA, Sacarlal J, Chilundo B, Gudo ES. Prescription practices for malaria in Mozambique: poor adherence to the national protocols for malaria treatment in 22 public health facilities. Malar J [Internet] BioMed Central. 2015;14:483. Available from: http://www.pubmedcentral.nih.gov/ articlerender.fcgi?artid=4667420\&tool=pmcentrez\&rendertype=abstract.

13. Okebe JU, Walther B, Bojang K, Drammeh S, Schellenberg D, Conway DJ, et al. Prescribing practice for malaria following introduction of artemetherlumefantrine in an urban area with declining endemicity in West Africa. Malar J. 2010;9:180.

14. Udoh E, Oyo-lta A, Odey F, Effa E, Esu E, Oduwole O, et al. Management of uncomplicated malaria in underfives in private and public health facilities in South-eastern Nigeria: a clinical audit of current practices. Malar Res Treat [Internet]. 2013;2013:575080. Available from: http://www.pubmedcentral.nih. gov/articlerender.fcgi?artid=3564278\&tool=pmcentrez\&rendertype=abstract.

15. Onwujekwe O, Kaur H, Dike N, Shu E, Uzochukwu B, Hanson K, et al. Quality of anti-malarial drugs provided by public and private healthcare providers in south-east Nigeria. Malar J. 2009:8:22.

16. NPC. The National Population Commission (NPC). 2006 Population and Housing Census of the Federal Republic of Nigeria. Priority tables (Volume I). Abuja, Nigeria: The National Population Commission 2009; 2009.

17. Minzi OHA. Poor knowledge on new malaria treatment guidelines among drug dispensers in private pharmacies in Tanzania: the need for involving the private - sector in policy preparations and implementation. East Africa J Public Heal. 2008;5:117-21.

18. Dikea N, Onwujekwea O, Ojukwuc J, Ikemed A, Uzochukwue B, Shud E. Influence of education and knowledge on perceptions and practices to control malaria in Southeast Nigeria. Soc Sci Medine. 2006;63:103-6.

19. $\mathrm{SMOH}$. Ogun State Malaria control program annual operational plan. 2014

20. Nigeria MIS NMCP (NMCP). Nigeria Malaria Indicator Survey 2010, vol. 123. 2012. Available from: http://dhsprogram.com/what-we-do/survey/surveydisplay-392.cfm

21. Skarbinski J, Ouma PO, Causer LM, Kariuki SK, Barnwell JW, Alaii JA, et al. Effect of malaria rapid diagnostic tests on the management of uncomplicated malaria with artemether-lumefantrine in Kenya: A cluster randomized trial. Am J Trop Med Hyg. 2009;80:919-26.
22. Mubi M, Kakoko D, Ngasala B, Premji Z, Peterson S, Björkman A, et al. Malaria diagnosis and treatment practices following introduction of rapid diagnostic tests in Kibaha District, Coast Region, Tanzania. Malar J. 2013;12:293.

23. Rowe a K, Onikpo F, Lama M, Cokou F, Deming MS. Management of childhood illness at health facilities in Benin: problems and their causes. Am J Public Health [Internet]. 2001;91:1625-35. Available from: http://www.pubmedcentral.nih.gov/ articlerender.fcgi?artid=1446844\&tool=pmcentrez\&rendertype=abstract.

24. Wasunna B, Zurovac D, Bruce J, Jones C, Webster J, Snow RW. Health worker performance in the management of paediatric fevers following inservice training and exposure to job aids in Kenya. Malar J [Internet]. 2010;9: 261. Available from: http://www.ncbi.n/m.nih.gov/pubmed/20849650.

25. Meremikwu M, Okomo U, Nwachukwu C, Oyo-Ita A, Eke-Njoku J, Okebe J, et al. Antimalarial drug prescribing practice in private and public health facilities in South-east Nigeria: a descriptive study. Malar J. 2007;6:55.

\section{Submit your next manuscript to BioMed Central and we will help you at every step:}

- We accept pre-submission inquiries

- Our selector tool helps you to find the most relevant journal

- We provide round the clock customer support

- Convenient online submission

- Thorough peer review

- Inclusion in PubMed and all major indexing services

- Maximum visibility for your research

Submit your manuscript at www.biomedcentral.com/submit
Biomed Central 